\title{
ADMISIBILIDAD DE LAS GRABACIONES SIN EL CONSENTIMIENTO DE QUIEN PARTICIPA Y SU DIVULGACIÓN
}

\section{ADMISSIBILITY OF RECORDINGS WITHOUT THE CONSENT OF THE SPEAKER AND ITS DISCLOSURE}

\section{ADMISSIBILIDADE DE GRAVAÇÕES SEM CONSENTIMENTO DO PARTICIPANTE E SUA DIVULGAÇÃO}

Camila Umpiérrez Blengio*

RESUMEN. La Suprema Corte de Justicia ha resuelto en el ámbito de un proceso penal que la grabación de una conversación no es prueba ilícita, siempre y cuando uno de los que haya grabado sea partícipe de la misma y el que posteriormente la difunda. A partir del análisis de doctrina y jurisprudencia nacional y extranjera, el presente trabajo se enfoca en la admisibilidad de las grabaciones de conversaciones sin un previo aviso al otro interlocutor y la admisibilidad de su divulgación a terceros sin autorización.

PALABRAS CLAVE. Grabación. Prueba. Constitución. Intimidad. Ilicitud.

ABSTRACT. A judgement by the Supreme Court of Justice in a criminal proceeding has concluded that recording a conversation is not inadmissible evidence, as long as one of those who has recorded participates in the conversation and is the one who subsequently disclosures it. Based on the analysis of the subject made by national and foreign legal scholars and case law, this paper focuses on the admissibility of recording conversations without prior notice to the other interlocutor and the admissibility of their disclosure to third parties without authorization.

KEY WORDS. Recording. Evidence. Constitution. Privacy. Unlawfulness.

RESUMO. No escopo de um processo criminal, o Supremo Tribunal de Justiça decidiu que a gravação de uma conversa não é uma evidência ilegal, desde que um dos sujeitos que gravou seja um participante e aquele que a divulgue posteriormente. Com base na análise da doutrina e jurisprudência nacional e estrangeira, este trabalho enfoca-se na admissibilidade das gravações de conversas sem aviso prévio ao outro interlocutor e a admissibilidade de sua divulgação a terceiros sem autorização.

PALAVRAS-CHAVE. Gravação. Prova. Constituição. Privacidade. Ilicitude.

I. INTRODUCCIÓN.

Desde la irrupción de la ciencia y la tecnología, el ordenamiento jurídico se ha visto en la necesidad de acompasarse a los cambios que estos fenómenos han generado.

COUTURE (1990) expresa con claridad que "el progreso del derecho debe mantener su

* Doctora en Derecho y Ciencias Sociales egresada de la Universidad de la República. Aspirante a Profesor Adscripto de Derecho Procesal, Facultad de Derecho, Universidad de la República. Correo electrónico: camila.umpierrez@hotmail.com 
natural paralelismo con el progreso de la ciencia; negarlo, significa negar el fin de la ciencia y el fin del derecho" (p. 262)

Los avances de la tecnología están llevando a la digitalización de la vida humana, y estos tienen un especial impacto en el campo de las comunicaciones. Cada vez es más habitual que las conversaciones mantenidas en cualquier ámbito sean grabadas por alguno de sus interlocutores, sin previo aviso del otro, generalmente mediante el dispositivo móvil. Asimismo, cada vez es más frecuente que se registren conversaciones mediante la utilización de cámaras y/o micrófonos, así como también a través de la grabación automática de las llamadas a organismos públicos o incluso, empresas privadas.

La admisibilidad de las grabaciones de conversaciones nos lleva a un punto largamente debatido por doctrina y jurisprudencia, tanto a nivel nacional como internacional: la conocida dicotomía entre la prueba y la verdad.

Esta temática necesariamente incide en la finalidad que se le atribuya al proceso jurisdiccional, ya sea como un instrumento orientado hacia la búsqueda de la verdad (de donde surgen diversas teorías sobre el concepto de la "verdad"') o por el contrario, el proceso como un instrumento privado de las partes con el objeto de la resolución de un conflicto intersubjetivo de intereses, cuya relación con la verdad es circunstancial.

II. ¿ES ADMISIBLE GRABAR UNA CONVERSACIÓN?

Como punto de partida, debemos distinguir dos escenarios: (i) la grabación de una conversación por parte de una persona que no es partícipe en dicha conversación y que lo hace sin el consentimiento de los interlocutores y; (ii) la grabación realizada por uno de los interlocutores partícipes de la conversación sin que el otro sepa que se está grabando $\mathrm{y}$, por ende, sin su consentimiento.

En el primer caso, esto es, la grabación por un sujeto ajeno al proceso de comunicación, nos encontramos frente a una actividad teñida de ilicitud. Cabe aclarar que se excluye de este supuesto la intervención, grabación o registro de comunicaciones telefónicas u otras formas de comunicación por orden judicial previstos en el art. 208 del Código del Proceso Penal. Asimismo, recordemos que la interceptación telefónica configura un delito tipificado por el Código Penal en su art. 297.

En este sentido, VALENTIN (2008) ha señalado que:

1-TARUFFO (2008) en su obra "La prueba", realiza un profundo y pertinente análisis respecto de la prueba y las teorías de la verdad: la verdad judicial, la verdad absoluta y la verdad relativa, la verdad como coherencia, la verdad como correspondencia (capítulo III). Señala TARUFFO:

La idea misma de "verdad judicial” puede parecer vaga, enigmática y dudosa (...) puede ya advertirse que la idea de las diferencias sustanciales que caracterizan la verdad judicial no puede sostenerse. En gran medida, la verdad puede ser buscada y alcanzada dentro del contexto judicial fundamentalmente de la misma forma en que se puede descubrir en muchas otras áreas de la experiencia cotidiana y usando los mismos medios que se emplean en áreas de investigación no jurídica, como la historia. Las normas jurídicas definen el contexto de la verdad "judicial”, pero -como ya se ha dicho antes- todo tipo de verdad es de algún modo "contextual". Es más, los hechos en litigio en una causa se suelen comprobar en el proceso judicial usando los mismos medios (testimonios, documentos, grabaciones, argumentos inferenciales) que la gente común y corriente utiliza para descubrir la verdad en su vida cotidiana. En resumen: no hay diferencia epistémica sustancial entre la verdad judicial y la verdad no judicial.

(TARUFFO, 2008, p. 25). 
Es indudable que la interceptación de una conversación telefónica por una persona que no es partícipe en dicha conversación, y que lo hace sin el consentimiento de los dos interlocutores, vulnera el derecho a la intimidad de los partícipes de la conversación (art. 72 de la Carta) y particularmente del derecho al secreto de las comunicaciones (arts. 27 y 28 de la Constitución). La grabación como tal es una prueba lícita, que integra el género de los documentos (C.G.P: art. 175.1). Sin embargo, si la misma es obtenida mediante la comisión de un acto violatorio de derechos constitucionalmente protegidos y eventualmente delictivo, como lo es la interceptación telefónica entre terceros, es contraria a la norma de derecho y consiguientemente ilícita. (p. 108).

En el segundo caso, cabe cuestionarse si la grabación de una conversación por parte de uno de los interlocutores de la misma, sin el consentimiento de los restantes, es una actividad lícita o no, por vulnerar derechos inherentes a la personalidad humana.

Es posible preguntarse los motivos por los cuales se graba una conversación, en tanto podría constituir un acto preparativo de su posterior difusión, que por ejemplo puede ser utilizado en un proceso jurisdiccional posterior. De esta forma, uno de los interlocutores es consciente de que está pre constituyendo prueba, aprovechando la intimidad de una conversación y la ignorancia del otro interlocutor respecto de que se lo está grabando.

De todas formas, debemos tener presente que lo se expresa en ese momento no escapa de los oídos de quien lo recibe ya que son palabras que van dirigidas a él. Por lo tanto, en el proceso de comunicación quien está escuchando puede tomar nota de lo que su interlocutor le manifiesta, tal como señala ABAL (2019):

Registrar lo que se expresa en una conversación - expresado tanto por la persona que quiere efectuar la grabación como por su interlocutor - podría hacerlo sin aviso alguno a la otra parte (ni previo ni posterior) a través del simple expediente de ir escribiendo en un papel lo que se está diciendo por uno o por ambos interlocutores (o escribiéndolo una vez finalizada la conversación) (p.14)

Respecto de este punto, lo que puede advertirse es que la grabación implica otras particularidades que no las tiene el registro por escrito de lo que se dijo en la conversación, como puede ser la grabación de la voz del interlocutor. En efecto, se ha sostenido que la voz del sujeto interlocutor tiene protección por su íntima relación con el derecho a la identidad, imagen y a la intimidad.

Sin perjuicio de estas consideraciones, entendemos que la grabación de la conversación por quien está participando de ella, aún en el supuesto que no exista consentimiento, no implica necesariamente una actividad ilícita. En efecto, la grabación en sí -al margen de su empleo ulterior- no está prohibida por nuestro ordenamiento jurídico. En este sentido, compartimos las conclusiones de ABAL (2019):

Conforme considero, ningún obstáculo existe en nuestro Derecho Positivo que impida registrar en un grabador de sonido el tenor de una conversación en la que quién graba 
está interviniendo, aún sin avisar de ello (ni pedirle autorización) al otro participante de la misma. Naturalmente que no me estoy refiriendo a la grabación de una conversación en la que no interviene quién está grabándola. En los supuestos que estamos analizando (y en el caso al que refiere la sentencia comentada) quién graba la conversación no está interceptando un intercambio al que es ajeno, sino que está grabando las palabras por él dirigidas a la otra persona y las palabras dirigidas por esa otra persona a él. No se están grabando palabras que quién está grabando no pueda legítimamente escucharlas (p. 14). III. ¿ES ADMISIBLE LA DIVULGACIÓN A TERCEROS DE LAS GRABACIONES DE CONVERSACIONES?

Ahora bien, la cuestión a dilucidar es si la grabación de una conversación aun cuando se entienda que fue lícitamente obtenida, puede ser posteriormente divulgada a terceros sin la autorización de todos los sujetos partícipes de la misma. Cabe aclarar que se excluyen los casos en donde la conversación está amparada bajo el secreto profesional, como puede ser la conversación mantenida entre un abogado y su cliente, o el médico y un paciente, donde el profesional tiene el deber de guardar secreto, lo que incluye la prohibición de divulgación a cualquier tercero.

En lo que refiere al proceso jurisdiccional, corresponde cuestionarse: a) si es admisible que una de las partes en el ejercicio de su derecho de defensa y particularmente del derecho a la prueba, incorpore una grabación y divulgue en un proceso concreto lo que le dijo la contraparte o; b) por el contrario, si esa grabación obtenida sin el consentimiento del interlocutor y que se quiere ofrecer como prueba es violatoria de los derechos inherentes a la personalidad humana, tales como el derecho a la intimidad y privacidad.

Nuestra Constitución no reconoce de forma expresa el derecho a la intimidad. Hay quienes encuentran el fundamento en el artículo 10 de la Constitución que expresa que las acciones privadas de las personas que no perjudiquen a terceros ni afecten el orden público están exentas de la autoridad de los magistrados. Otros prefieren encontrar su fundamento en el artículo 72 de la Constitución, comprendido dentro de los "derechos inherentes a la personalidad humana". El derecho a la intimidad junto con el derecho al honor y el derecho a la propia imagen, forman parte integrante de una trilogía de derechos inherentes a la autonomía personal (RISSO, 2006, p. 575). FRANCA-TARRAGÓ (2002) citado por RISSO (2006, pp. 575-576) recuerda que:

La intimidad tiene un contenido relativamente amplio y comprende: (a) aspectos y circunstancias de la vida familiar (nacimientos, matrimonios, divorcios, embarazos, fallecimiento, vida sexual, costumbres, etc); (b) vida intelectual (currículo personal, notas académicas, escritos e investigaciones no publicados, etc); (c) aspectos y circunstancias de los esparcimientos (actividades y amistades de vacaciones, lugares de descanso, etc); (d) circunstancias del pasado (orígenes familiares, cuestiones concernientes a la filiación y a la descendencia étnica, etc); (f) proyectos de futuro (posibilidades de trabajo o estudio, 
decisiones a tomarse, etc); (g) vida de relaciones (amistades, odios, prácticas sociales, correspondencia, etc); (h) circunstancias económicas (bienes de los que se es propietario, deudas, situación tributaria, etc); (i) circunstancias religiosas o políticas; (j) circunstancias sanitarias tales como enfermedades, estados mentales, etc.

Por otra parte, el derecho a la prueba integra el principio del debido proceso legal recogido en el art. 12 de nuestra Constitución y es una manifestación o derivado del derecho de acción en el caso del actor o contradicción en el caso del demandado (art. 11.1 C.G.P.). La Suprema Corte de Justicia (Sentencia No. 1280/2015, del 31/08/2015) ha expresado que:

El derecho a ofrecer prueba en sustento de la pretensión integra las garantías básicas del debido proceso legal y como enseña la doctrina especializada, el derecho a la prueba es un aspecto fundamental del derecho de acción y a la defensa (v. Taruffo, La Prueba, Artículos y Conferencias, p. 79, Ed. Metropolitana).

Asimismo, la jurisprudencia de los Tribunales de Apelaciones - en su mayoría - han reiterado en estos últimos años que:

El derecho a probar o intentar hacerlo forma parte esencial de las garantías de la defensa en juicio, e integra la noción de debido proceso, en el ámbito procesal iberoamericano y en el ordenamiento jurídico nacional (arts. 12 y 18 de la Constitución de la República; 8 de la Convención Interamericana de Derechos Humanos; 11, 137 y 139 del Código General del Proceso ${ }^{2}$.

En doctrina nacional, VALENTIN (2008) ha señalado que el derecho a la prueba implica: La posibilidad de ambas partes de proponer medios de prueba, controlar las decisiones del tribunal sobre la admisibilidad de la prueba, a participar en su diligenciamiento, a proponer la valoración del resultado probatorio y a controlar la sentencia del tribunal que valora la prueba (arts. 12 y 16). (p.106)

Ninguna norma puede limitar la proposición de pruebas que sean legítimas, idóneas y referidas al objeto del proceso (VALENTIN, 2017). Por lo tanto, las limitaciones al derecho a probar únicamente radican en la no afectación de los derechos constitucionalmente reconocidos. Como señala VALENTIN (2008):

Es inconstitucional no solo la prueba obtenida en violación de las normas sustanciales de la Constitución, sino también aquella obtenida en violación de las normas procesales contenidas en la misma Carta. Por consiguiente, no solamente son inconstitucionales las pruebas que se obtienen o producen vulnerando los derechos al honor, la libertad, la propiedad (art. 7), a la inviolabilidad del domicilio (art. 11) y de los papeles de los particulares y su correspondencia particular, telegráfica o de "cualquier especie" (art. 28), etc., sino también aquellas que admiten o diligencian violando, por ejemplo, los derechos de

2 -Ver Sentencias: TAC $5^{\circ}$ Nro. 8/2008; TAC $5^{\circ}$ Nro. 91/2009; TAC $4^{\circ}$ Nro. $113 / 2009$; TAC $7^{\circ}$ Nro. 46/2011; TAC $5^{\circ}$ Nro. 87/2012; TAC $4^{\circ}$ Nro. 123/2012; TAC $4^{\circ}$ SEI-0009-000022/2014; TAC $5^{\circ}$ Nro. 0004-000276/2014; TAC $5^{\circ}$ Nro. i40/2016; TAC $4^{\circ}$ SEF-0009-000034/2016. 
igualdad, bilateralidad, contradicción e imparcialidad (arts. 8, 21 y 22, entre otros). Sin embargo, es preciso reconocer que tradicionalmente se ha denominado "prueba ilícita" a la primera, reservando para la segunda el nombre de "prueba ilegítima" o "prueba ilegítimamente admitida". (p. 107)

Asimismo, en el ámbito del proceso penal, MINVIELLE (1985), recordando la opinión de PELLEGRINI GRINOVER, señala que:

Cuando, en la obtención de la prueba se hubieren infringido derechos y garantías constitucionales, expresa o implícitamente consagrados, la prueba será inadmisible procesalmente, aún cuando no exista norma procesal que así lo establezca, puesto que, los derechos y libertades del individuo constituyen un límite a la función jurisdiccional. La prueba obtenida en violación de derechos fundamentales es prueba inconstitucional. (p.163). Pues bien, la posibilidad de hacer valer en un proceso la grabación de una conversación obtenida sin consentimiento del interlocutor, podría afectar el derecho a la intimidad. Pero, por otro lado, puede argumentarse que la búsqueda de la verdad que tiene lugar en el proceso, así como el ejercicio del derecho de defensa pueden enfrentarse con este derecho inherente a la personalidad humana. Se trata entonces de resolver la antinomia que en tales casos se crea.

Recientemente se ha pronunciado ABAL (2019) en postura que resulta sumamente interesante, haciendo énfasis en el derecho de defensa:

Si quién grabó la conversación sin noticia de su interlocutor -aunque el contenido refiera a aspectos del derecho a la intimidad de este interlocutor- igual puede exponerlo en un juicio en defensa de su derecho (esto es, porque no hay secreto profesional, y porque al existir ese proceso se presenta lo que se entiende que es una justa causa), entonces también puede incorporarse en ese juicio a la grabación en caso de existir la misma (sin perjuicio de la reserva que según el caso podría corresponder frente a terceros, y que la legislación procesal autoriza al juez a disponer). En definitiva, si es admisible que un interlocutor exprese en un proceso jurisdiccional lo que le dijo el otro interlocutor, entonces el primero puede también pedirle a testigos que lo confirmen, o interrogar sobre ello al otro interlocutor, o formularle una absolución de posiciones, o agregar una grabación de sus palabras. Se dirá que, si el emisor de las palabras sabía que las mismas se iban a reproducir por su interlocutor, o repetir por testigos, o que se le iba a plantear en juicio que confirmara que las había dicho, o que se iba a presentar en el juicio una grabación de lo expresado, entonces no las habría pronunciado. Pues -discrepando con el juez cuya sentencia da origen a este artículo- entiendo que esto para nada importa, si es que al reproducirse en el juicio el intercambio por cualquiera de estas formas y sin que medie secreto profesional, lo que se está haciendo es intentando defender un derecho que el emisor de las palabras está desconociendo en forma ilegítima. En este mismo sentido expresa MINVIELLE (Bernadette, "El derecho a la intimidad y la prueba en el Proceso Penal, con especial referencia a las 
interceptaciones telefónicas", Rev. Uruguaya de Derecho Procesal, Montevideo, 2/1985, pág. 159): "La conducta debe haber sido llegada a cabo sin justa causa. La doctrina ubica como hipótesis de justa causa: el consentimiento del remitente; ejercicio legítimo de un derecho como lo sería su presentación en juicio para probar contra el remitente, un hecho falsamente alegado por el mismo (...)". (pp.15-16)

Teniendo en consideración el análisis desarrollado, entendemos que existen algunos aspectos que nos parecen claves para evaluar la admisión y producción de una grabación en un proceso jurisdiccional, ante la oposición de la parte contra quien se quiere hacer valer la grabación: (i) que quien grabe y divulgue la conversación haya sido uno de los partícipes -interlocutores- de la misma; (ii) que no se trate de conversaciones amparadas bajo el secreto profesional, (iii) que el interlocutor que grabó la conversación pueda valerse de otros medios de prueba para intentar acreditar el contenido de la conversación mantenida. Por ejemplo, ofrecer la declaración de un testigo que sin participar de la conversación estuvo presente en el momento en que se mantuvo la misma (imaginemos una conversación en una oficina de trabajo entre dos compañeros y otro los escucha ya que trabaja en el mismo espacio físico); (iv) el ejercicio legítimo del derecho de defensa, para desmentir un hecho falsamente alegado en el proceso.

Finalmente, cabe destacar que será tarea del magistrado que intervenga en el caso concreto analizar la prueba ofrecida por las partes para determinar, ante una controversia planteada en el proceso, si se trata de una prueba obtenida de forma ilícita o no. Así como también, su posible exclusión por resultar inadmisible (arts. 24 num. 6, 144.1 y 341 num. 6 del C.G.P) o el valor probatorio que le otorga, lo cual puede significar una simple presunción y en otras circunstancias puede llegar a constituir una prueba decisiva. Por último, debemos recordar que la admisión y producción de la prueba no impide que la misma sea descartada por el magistrado al dictar sentencia definitiva.

IV. LA JURISPRUDENCIA NACIONAL.

La jurisprudencia uruguaya, en su mayoría, ha sostenido que la grabación de una conversación sin el consentimiento de todos los sujetos intervinientes es prueba ilícita en tanto vulnera derechos como la intimidad de las personas, la privacidad, la inviolabilidad o secreto de las comunicaciones.

En efecto, en estos últimos años la jurisprudencia nacional ha compartido la argumentación que fuera sostenida en Sentencia Nro. 204/2011, dictada por el Tribunal de Apelaciones en lo Civil de $5^{\circ}$ Turno, integrado por los Dres. Simón, Fiorentino y Gradín con fecha 14 de Diciembre de 2011. En la referida Sentencia, se considera ilícita la prueba incorporada en un CD que contenía la conversación mantenida entre el actor, el demandado y otra persona y que fuera grabado sin conocimiento ni consentimiento del demandado. Por motivos de extensión únicamente transcribimos el siguiente pasaje de la misma:

Puede conceptualizarse la especie de prueba ilícita que se intentó en autos a través de la 
grabación y transcripción de su contenido, como aquella que se encuentra afectada por una conducta dolosa en cuanto a la forma de obtención, es decir, la prueba que ha sido lograda en forma fraudulenta, a través de una conducta ilícita o direccionada a tal fin. Se trata de una especie dentro de la prueba ilícita, género que en definitiva comprende a toda prueba violatoria del ordenamiento jurídico en general, ya sea porque el medio probatorio en sí mismo es ilícito, o porque siendo lícito, su origen, obtención o producción se ven afectados por violación normativa en sentido amplio, particularmente, por transgresión de las disposiciones y principios constitucionales que reconocen derechos a las personas. Así las cosas, la grabación obtenida con la participación de quien y contra quien se hará valer dicha prueba, sin su conocimiento ni consentimiento, debe reputarse ilícita; violatoria de derechos inherentes a la personalidad humana, tales como los derechos a la intimidad, privacidad, etc. (art. 72 de la Constitución de la República) así como vulneratoria de la moral y buenas costumbres. Por ende, resulta carente de eficacia probatoria en el plano jurídico.

La prueba ilícita, así como su efecto más próximo (que se conoce como la "doctrina del fruto del árbol envenenado" o "fruit of the poisonous tree doctrine") configuran medios de prueba inválidos, ineficaces, totalmente improductivos a la hora de poder ser valorados por el órgano jurisdiccional para fundar una decisión, incumbiendo al Tribunal el poder-deber de impedir su incorporación al proceso, por inadmisibilidad, en base a lo establecido por los arts. 6, 24 apartados 6.y 9, 146.2, 144.1, 341 numeral 6 y concordantes del Código General del Proceso).

La fundamentación de esta Sentencia fue posteriormente reproducida en otras sentencias ${ }^{3}$. Recientemente, con fecha 2 de mayo de 2019, el Juzgado Letrado en lo Contencioso Administrativo de 1er. turno ha dictado la Sentencia Interlocutoria Nro. 884/2019 en la que considera ilícita una grabación inconsulta por la vulneración del principio de confianza legítima. A continuación, transcribimos algunos pasajes:

... el oficio entiende que toda grabación subrepticia de una conversación en la que es parte quien efectúa el registro (no existe por tanto "interceptación" de comunicaciones de terceros) violenta el principio de confianza legítima entre las personas que participan de ese intercambio verbal, por tanto, se trata de prueba inadmisible o ilícita, art 144.1 del C.G.P. (...)

15.- Esa legítima confianza se quiebra si válidamente uno de los partícipes puede grabar la conversación sin dar previo aviso a los demás sujetos, quebrantando los Derechos Constitucionalmente protegidos del emisor del mensaje, a la seguridad y a la libertad, art 7 de la Carta.

3 -TAT $3^{\circ}$ en Sentencia Nro. 541/2012, de 03.10.2012, SCJ en Sentencia Nro. 496/20104 de 15.05.2014, integrada por los Dres. Jorge O. Chediak, Julio Cesar Chalar Vecchio, Jorge T. Larrieux, Jorge Ruibal Pino y Ricardo Pérez Manrique. Recientemente, TAC $2^{\circ}$ en Sentencia Nro. SEF-005-000218/2018 de 19.12.2018 y TAF $2^{\circ}$ en Sentencia Nro. SEF 11$77 / 2018$ de 16.05 .2018 . 
16.- Se reitera, si este hubiera querido dar a conocer el contenido del diálogo a terceros, hubiera utilizado otra vía de comunicación. En este punto, se comparte con el demandado que se hipotecan los principios que emanan de la personalidad humana, a la intimidad y privacidad, art 72 de la Constitución, que expresan los demandados (fs 439 mitad).

17.- La grabación obtenida sin anuencia o conocimiento de quien es registrado, es prueba ilícita porque violenta caros principios Constitucionales, además que de aceptarse esta posibilidad con validez probatoria, significaría la muerte en el Estado de Derecho de la libertad de expresión en los diálogos y terminaría convirtiendo a cada individuo en un paranoico que al emitir cualquier concepto, aún en conversaciones íntimas, tendría temor de que sus dichos fueran luego utilizados, vaya a saber, con qué propósito o en qué ocasión. 18.- Este es el punto neurálgico, porque desde la perspectiva de quien registra una conversación de modo secreto y sin avisar a su interlocutor, existe la convicción de que, en caso de mediar aviso del registro, aquel no se expresaría libremente. Es decir que también el que graba de forma oculta lo hace porque supone que existe la confianza legítima entre los individuos de expresarse con libertad y en la seguridad de que lo expresado será exclusivamente de conocimiento de quien o quienes estaban presentes, este es el componente doloso a que aluden correctamente los demandados y el Oficio comparte (fs 437 vto).

19.- En el Estado de Derecho el fin no justifica los medios, en consecuencia, prevalecen las normas tutelares de la Constitución que obturan la validez del medio probatorio propuesto habida cuenta de su ilicitud.

20.- Esta prevalencia de los Derechos Constitucionales del emisor del mensaje, no admite distingo, es decir, no cambia la conclusión si el que participa de la conversación es un funcionario Público, que por el hecho de actuar con criterios de veracidad y legalidad, igualmente amparado en la legítima confianza de la reserva de una conversación puede emitir conceptos, opiniones o sugerencias bien intencionadas a otro individuo, que si supiese que están siendo grabadas no haría.

21.- Que paradoja, en un mundo en que la vida privada de las personas no existe, el temor es expresarse sinceramente y sin tapujos en conversaciones particulares

En definitiva, según los argumentos señalados por la jurisprudencia nacional, la grabación de una conversación realizada por uno de los interlocutores sin el conocimiento del otro de los interlocutores y consecuentemente sin su consentimiento expreso o tácito, constituye prueba inadmisible.

Fundamentan la ilicitud de la prueba en la vulneración de los derechos de la personalidad (sobre todo, el derecho a la intimidad) o el principio de confianza legítima (en tanto la grabación inconsulta es un acto que resiente la relación de confianza).

IV.1. La grabación no consentida no es prueba ilícita: ¿un cambio en la jurisprudencia nacional?

Resulta de gran interés para el ámbito académico así como de relevancia práctica destacar 
lo resuelto recientemente por la Suprema Corte de Justicia (SCJ).

En efecto, por Sentencia Nro. 1.153/2019 de fecha 30 de mayo de 2019, la SCJ (integrada por los Dres. Martínez, Minvielle, Chediak, Turell y Tosi) ha resuelto que aun cuando se trata de una grabación no consentida, realizada y difundida por uno de los interlocutores, no estamos ante un supuesto de prueba ilícita.

En primer lugar, cabe destacar que se trata de una sentencia dictada en una casación en materia penal. Es cierto que en el ámbito del proceso penal se han postulado excepciones o atenuaciones a la regla de que el medio de prueba ilícitamente obtenido no puede ser incorporado al proceso. Un sector de la doctrina se pronuncia a favor de admitir algunas excepciones a la inadmisibilidad de la prueba ilícita en función de los criterios de razonabilidad y proporcionalidad, admitiéndola cuando es el único instrumento para evitar daños de mayor gravedad en el caso concreto y sólo en la medida de evitar dicho daño (MINVIELLE, 1985).

La jurista brasileña PELLEGRINI (1993), citada por KLETT (2018, p. 467), señala: “La teoría de la inadmisibilidad procesal de las pruebas ilícitas puede ser mitigada por el principio de la proporcionalidad, que pone en confrontación valores constitucionalmente relevantes".

También ha señalado PELLEGRINI (1993) que "en el proceso penal, por lo menos en un caso, ha de encontrar aplicación el principio de proporcionalidad: es el de la prueba ilícita que favorezca al acusado, que debe ser admitida, con vistas a la preeminencia del valor libertad y del principio de inocencia, en contraposición con otros valores (intimidad, sigilo de las comunicaciones, inviolabilidad del domicilio, etc)"

Por otro lado, GARDERES y VALENTIN (2016) sostienen que:

Es preferible no admitir excepciones en el principio de la no incorporación al proceso, en contra del imputado, del elemento de prueba obtenido directamente en violación de disposiciones constitucionales o legales. En este sentido, como señala CAFFERATA NORES (p.18): otorgarle a la desobediencia de la Constitución alguna eficacia (aun indirecta) significaría estimularla en la práctica. Cierto es que esta solución puede llevar a la impunidad de algún delito. Pero no lo es menos que el orden jurídico ha optado, en muchos casos, por la impunidad, cuando ella ha sido el precio de la tutela de otros intereses que ha considerado más valiosos que el castigo del ilícito, dándoles una protección de rango constitucional (pp. 479-482).

En cuanto al régimen procesal penal, el actual Código del Proceso Penal en su art. 144 inc. $1^{\circ}$ admite cualquier medio de prueba "salvo que se encuentren expresamente prohibidos por la Constitución Vigente de la República o la ley".

Sin perjuicio de este análisis, sería posible concluir que los conceptos vertidos en la Sentencia de la SCJ respecto de las grabaciones sonoras podrían resultar válidos y extensibles para procesos en el ámbito civil. Veremos incluso que la propia SCJ no hace referencia 
a ninguna excepción o atenuación por tratarse de un proceso penal, sino que maneja este análisis de su admisibilidad desde una óptica general.

A continuación, analizamos el caso planteado ante la SCJ:

Quien interpone el recurso de casación se había agraviado por la admisión de prueba que consideró ilícita: un video de una reunión en la oficina de un empresario, en el cual el recurrente - un agente policial - y su compañero - otro agente policial -, concertaban incriminar falsamente a un competidor del empresario, recibiendo en ese acto como adelanto del pago de sus servicios un fajo de dinero.

La SCJ consideró que no le asistía razón al recurrente por las siguientes razones:

En primer término, cabe señalar que la interpretación del agravio, a la luz de lo que surge del recurso y de lo expresado por la parte en diversas oportunidades procesales -fojas 312-317-, impone considerar si, efectivamente, estamos ante una prueba ilícita por haber sido obtenida de forma antijurídica, en violación del derecho a la intimidad del co-encausado, aspecto al que cabe considerar que se aludió al sostenerse que, al contrario de lo que afirmó la Sala, la grabación no fue introducida lícitamente al proceso, ya que se vulneró el derecho a la intimidad y al secreto de las comunicaciones de los coencausados M.M. y R.R..

Tal aspecto, medular y determinante de la eventual configuración de un supuesto de prueba ilícita, ha sido sostenido desde el inicio del proceso al afirmarse por M.M. -y R.R.- que estábamos ante una grabación clandestina o subrepticia y que, por tal calidad, era inadmisible.

No estamos ante un supuesto de prueba ilícita aun cuando se trata de una grabación no consentida.

En primer lugar, porque se comparte plenamente el criterio seguido por la jurisprudencia española sentencia del Tribunal Supremo español del 3 de mayo de 2006-, conforme al cual son admisibles "las grabaciones subrepticias, siempre que quien grabe y difunda sea uno de los interlocutores en la comunicación, por no entenderse vulnerado en tal caso el derecho al secreto de las comunicaciones" (Armenta Deu, Teresa, La prueba ilícita (un estudio comparado, Marcial Pons, $2^{\mathrm{a}}$ ed., 2011, p. 91). Y ello exactamente es lo que aconteció en el caso, en el cual el empresario D.D. aparece preparando la cámara en su oficina para registrar la reunión con los policías M.M. y R.R.).

Como surge de autos, el video sería aportado más adelante por la que fuera abogada de D.D., Adriana Ramos, luego de que la relación con su ex cliente se deteriorara enormemente, aduciendo la Dra. Ramos que recibió la copia en forma anónima.

El hecho de que, incontestablemente, la grabación haya sido realizada por uno de los co-imputados, impide considerar que estemos ante una prueba ilícita, razón suficiente para desestimar el agravio.

En segundo lugar, adicionalmente, cabe considerar que aun cuando se soslayara lo an- 
terior o no se compartiera, la grabación de la reunión de marras en forma subrepticia no configura un supuesto de prueba ilícita desde que registra la comunicación de dos funcionarios públicos en el ejercicio de su función, ejercicio desviado e ilícito claro está, pero ejercicio de función pública al fin de cuentas. En efecto, R.R. y M.M. concurrieron a la reunión en virtud de su cargo y función, acordando incriminar falsamente a un competidor de D.D., como de modo harto elocuente lo demuestra la transcripción no cuestionada del video de autos (fojas 100 y siguientes). En tal sentido, afirmando la ausencia de ilicitud de la prueba consistente en grabaciones subrepticias de funcionarios públicos ("cámara oculta"), se pronunció el Tribunal de lo Contencioso Administrativo (TCA) en sentencia nro. 591/2011.

En tal fallo, el TCA señaló: “la resistida grabación no representa 'prima facie' una violación al derecho a la intimidad de los Sres. Contadores que asistieron a la reunión, en representación del Organismo demandado; y ello porque (...) asistieron en su calidad de funcionarios públicos -y por lo que surge de las expresiones de las partes, lo hicieron en observancia de las indicaciones impartidas por las autoridades del Ente recaudador-. Prueba de ello, es que la propia DGI admite 'haber acordado dicha reunión por su iniciativa', por lo cual resulta difícil admitir una oposición, que violentaría el derecho a la intimidad, ya que, de acuerdo a la opinión del Profesor Miguel Torres 'no existen obstáculos legales para que las labores de investigación, se extiendan a la captación de imágenes de personas, de manera vedada o subrepticia: el interés público que subyace en la investigación, justifica no las injerencias en la vida privada, ni a los atentados a la intimidad o dignidad pero sí un seguimiento de los pasos de determinadas personas' (Cf. Torres Morato, Miguel, ['La prueba ilícita penal']).

Resulta interesante el análisis que realiza la SCJ en tanto parte de la distinción de dos escenarios: por un lado, la grabación de una conversación que realiza uno de los partícipes de la misma y, por otro lado, la grabación de una conversación por un tercero ajeno al proceso de comunicación.

Así concluye la SCJ que la agregación de la grabación que contenga una conversación no es prueba ilícita aun cuando no sea consentida, por dos razones: a) el que grabó es partícipe de la misma y el que posteriormente la difundió y b) se registró la comunicación de dos funcionarios públicos en el ejercicio de su función pública, ejercicio desviado e ilícito.

La Sentencia de la SCJ en análisis se apoya en lo resuelto por la jurisprudencia extranjera, en este caso, la española, haciendo eco de la Sentencia del Tribunal Supremo Español del 3 de mayo de 2006. Sin perjuicio de que se trata de una sentencia que fue dictada hace más de 10 años, mediante un relevamiento actual hemos constatado que la jurisprudencia española en materia penal mantiene la misma postura: no existe violación al derecho a la intimidad cuando uno de los interlocutores graba y difunde una conversación que mantuvo con otro. 
En efecto, la Sección Cuarta de la Sala de lo Penal de la Audiencia Nacional Española en Sentencia Nro. SAN 973/2018 del 09/04/2018 señala que:

Entiende el tribunal que en el caso de autos el tema es radicalmente distinto. No se trata de colocar micrófonos, con autorización judicial en un sitio en el que más tarde van a acudir los investigados; se trata de grabar las conversaciones que se producen entre un testigo (el agente encubierto) y alguno de los acusados en el periodo durante el que el agente estaba realizando su cometido dentro del grupo terrorista investigado. Es decir, se trata de que el tribunal conozca, de primera mano, cuales fueron exactamente el contenido de las conversaciones de alguno de los acusados que permitan deducir su participación en el delito de pertenencia a organización terrorista que estaba siendo investigado.

La citada forma de actuar ha sido considerada acorde a derecho en otros supuestos similares, así, en las sentencias del T.S. de 05/04/2017 y 02/02/2017. Esta última dice: "La doctrina jurisprudencial de esta Sala, así como emanada del Tribunal Constitucional (SSTS n ${ }^{\circ}$ 208/2006, de 20 de febrero , 1564/1998, de 15 de diciembre, 1354/2005, de 16 de noviembre; STC n ${ }^{\circ} 56 / 2003$, de 24 de marzo), sobre la garantía constitucional del secreto de las comunicaciones sólo opera cuando la injerencia es realizada por una persona ajena al proceso de comunicación, ya que lo que persigue la norma es garantizar la impenetrabilidad de la comunicación por terceros ajenos a la misma" y así lo declaró ya la STC no 56/2003, de 24 de marzo: "la presencia de un elemento ajeno a aquéllos entre los que media el proceso de comunicación, es indispensable para configurar el ilícito constitucional aquí perfilado", y sigue diciendo: "Solo podrá vulnerarse el derecho fundamental reconocido en el art. 18.3 cuando se graba la conversación de otro, pero no cuando se graba una conversación con otro". Conforme a la STC 114/1984, de 29 de noviembre, "no hay secreto para aquél a quien la comunicación se dirige, no implica contravención de los dispuesto en el art. 18.3 de la Constitución la retención, por cualquier medio, del contenido del mensaje, pues sobre los comunicantes no pesa el deber del secreto.

Asimismo, la jurisprudencia española tampoco entiende que la grabación per se de una comunicación viole el derecho a la intimidad del interlocutor que está siendo grabado.

La STS de 26/06/2015 ha declarado que no constituye contravención alguna del secreto de las comunicaciones la conducta del interlocutor en la conversación que graba ésta. La grabación en sí -al margen su empleo ulterior- sólo podría constituir un ilícito sobre la base del reconocimiento de un hipotético «derecho a la voz» que no cabe identificar en nuestro ordenamiento, por más que sí pueda existir en algún Derecho extranjero. Tal protección de la propia voz existe sólo, en el Derecho español, como concreción del derecho a la intimidad y, por ello mismo, sólo en la medida en que la voz ajena sea utilizada ad extra y no meramente registrada, y aun en este caso cuando dicha utilización lo sea con determinada finalidad (art. 7.6 LO 1/1982: «utilización de la voz de una persona para fines publicitarios, comerciales o de naturaleza análoga) (Sentencia Nro. SAN 973/2018 
del 09/04/2018 de la Sección Cuarta de la Sala de lo Penal de la Audiencia Nacional Española)

En igual sentido, la Sentencia STS Nro. 239/2010 de 24 de marzo de 2010 dictada por el Tribunal Supremo Español - Sala Segunda de lo Penal, declara que la grabación por uno de los interlocutores de la conversación telefónica:

No conculca secreto alguno impuesto por el art. 18.3 y tan solo, acaso, podría concebirse como conducta preparatoria para la ulterior difusión de lo grabado. Por lo que a esta última dimensión del comportamiento considerado se refiere, es también claro que la contravención constitucional solo podría entenderse materializada por el hecho mismo de la difusión... Los resultados prácticos a que podría llevar tal imposición indiscriminada de una obligación de silencio al interlocutor son, como se comprende, del todo irrazonables y contradictorios, en definitiva, con la misma posibilidad de los procesos de libre comunicación humana". De ahí que concluya: "Conforme a dicha doctrina la grabación de las palabras de los acusados realizadas por el denunciante con el propósito de su posterior revelación, no vulnera ningún derecho al secreto, ni a la discreción, ni a la intimidad, pues no se alcanza a comprender el interés constitucional que podría existir en proteger el secreto de los propósitos delictivos (SSTS n $386 / 2002$, de 27 de febrero, 883/1994, de 11 de mayo, 977/1999, de 17 de junio).

\section{REFLEXIONES FINALES.}

La grabación de una conversación por parte de una persona que no es partícipe de la misma y que lo hace sin el consentimiento de los interlocutores, es una actividad teñida de ilicitud. Se violan derechos constitucionalmente protegidos y puede resultar una actividad delictiva (interceptación telefónica entre terceros).

Por otro lado, la admisibilidad de una grabación realizada por un sujeto partícipe de la conversación sin el consentimiento de su interlocutor y su posterior divulgación es una problemática que a la fecha no ha sido resuelta de forma expresa por nuestro ordenamiento jurídico.

Esto implica que tanto doctrina como jurisprudencia mantengan posturas disímiles al respecto y que finalmente el asunto se termine dilucidando en un proceso jurisdiccional concreto, lo que dependerá de diversos factores. En particular, será decisiva la oposición de la parte contra quien se quiere hacer valer la grabación y la valoración que realice el magistrado respecto de la posible afectación al derecho a la intimidad.

En nuestro país no hay norma que consagre un sistema de jurisprudencia obligatoria ni aun cuando las sentencias sean reiteradas. Por lo tanto, la jurisprudencia de la SCJ no tiene efectos ante otros tribunales ni genera precedentes para la propia Corte. No obstante, resulta de sumo interés tener presente lo resuelto recientemente en un proceso penal en relación a la admisibilidad de las grabaciones inconsultas y su difusión por quien participó de la conversación. 
En efecto, en el año 2019 la SCJ ha considerado que la agregación de una grabación que contenga una conversación no es prueba ilícita aun cuando no sea consentida, siempre y cuando uno de los que haya grabado sea partícipe de la misma y el que posteriormente la difunda. En este supuesto, considera la SCJ que no se estaría violando el derecho a la intimidad o a la inviolabilidad de las comunicaciones.

Cabe cuestionarse si lo resuelto por la SCJ en un proceso penal es válido y extensible a cualquier otro proceso que no verse sobre materia penal. En la sentencia a estudio, la SCJ no hace referencia a ninguna excepción o atenuación por tratarse de un proceso penal, sino que maneja este análisis de admisibilidad desde una óptica general. Asimismo, la SCJ hace eco de la jurisprudencia española en materia penal que ha entendido que no existe violación al derecho a la intimidad cuando uno de los interlocutores graba y difunde una conversación que mantuvo con otro.

\section{BIBLIOGRAFÍA CONSULTADA.}

ABAL OLIÚ, Alejandro (2015). Derecho Procesal, Tomo IV, $2^{\circ}$ Edición, FCU, Montevideo.

ABAL OLÍU, Alejandro (2019). "Prueba a través de grabaciones sonoras", en Revista Uruguaya de Derecho Procesal 2/2018, FCU, Montevideo.

ALVAREZ PETRAGLIA, Federico (2013). "Escuchas telefónicas, derecho a la intimidad y Estado de Derecho", en Dos estudios sobre el Debido Proceso Legal, Carlos Alvarez Editor, Montevideo.

CABRERA, Rafael (2019). "Prueba ilícita", en XIX Jornadas Nacionales de Derecho Procesal, FCU, Montevideo.

COUTURE, Eduardo (1990). Fundamentos del Derecho Procesal Civil, $3^{\circ}$ Edición, Depalma, Buenos Aires.

DEVIS ECHANDÍA, Herando (2002). Teoría general de la prueba judicial, Tomo1, $5^{\circ}$ Edición, Editorial Temis, Bogotá, Colombia.

GARDERES, Santiago y VALENTIN, Gabriel (2016). Código del Proceso Penal. Comentado, $2^{\mathrm{a}}$ ed., La Ley Uruguay, Montevideo.

JULIANO GARBARIN, Lorena (2018). "Las nuevas tecnologías y su influencia en el Derecho Laboral" en Judicatura $\mathrm{N}^{\circ}$ 64, Montevideo.

KLETT, Selva, BALUGA, Cecilia, ÁlVAREZ, F.; CASTILLO, J. (2000); "Principios de la prueba en el sistema procesal civil", en Revista Uruguaya de Derecho Procesal, Nro. 1/2000, FCU, Montevideo.

KLETT, Selva (2014). Proceso ordinario en el Código General del Proceso, t. II, FCU, Montevideo.

KLETT, Selva (2018). "Reglas generales de la prueba” en Curso sobre el Nuevo Código 
del Proceso Penal - Ley No. 19.293-", Volumen 1, Instituto Uruguayo de Derecho Procesal, Facultad de Derecho, Universidad de la República, FCU, Montevideo.

LANDONI, Angel (Director), GARDERES, Santiago, GONZALEZ, María Eugenia, GOMEZ, Fernando, VALENTIN, Gabriel (2003). Código General del Proceso, Vol. 2-A, B. De F., Buenos Aires.

LANDEIRA, Raquel (2006). "Tendencias jurisprudenciales en materia de prueba ilícita en los juicios penales", en Revista Uruguaya de Derecho Procesal 3/2006, FCU, Montevideo.

LELES DA SILVA, Mariella (2019). "El documento electrónico como medio de prueba", en XIX Jornadas Nacionales de Derecho Procesal, FCU, Montevideo.

MATTOS, Matías; TASENDE, Ignacio (2019). "Incorporación de la prueba electrónica al proceso. Admisibilidad, producción y valoración ¿una tarea artesanal en la era digital”, en XIX Jornadas Nacionales de Derecho Procesal, FCU, Montevideo.

MINVIELLE, Bernadette (1985). "El derecho a la intimidad y la prueba en el Proceso Penal, con especial referencia a las interceptaciones telefónicas", en Revista Uruguaya de Derecho Procesal 2/1985, FCU, Montevideo.

MINVIELLE, Bernadette (1987). "La Convención Americana sobre Derechos Humanos", en Revista Uruguaya de Derecho Procesal, 2/1987, FCU, Montevideo.

MINVIELLE, Bernadette (1987). "La prueba ilícita en el derecho procesal penal”, Opúsculos de Derecho Penal y Criminología $N^{\circ}$ 25, Marcos Lerner Editora Córdoba SRL, Argentina.

MONTERO, Jorge R (año). Después de la exclusión de la prueba ilícita ¿qué?. Tesis inédita con la que obtuvo el grado de Doctor en Derecho y Ciencias sociales en la Universidad Nacional de Córdoba.

PEREIRA, Santiago (2013). Código General del Proceso. Reformas de la ley 19.090, Universidad de Montevideo, Montevideo.

PICARDO, Sebastián; TISCORNIA, Andrés (2019). "Prueba documental y tecnología. Régimen de admisibilidad, producción y valoración de la prueba", en XIX Jornadas Nacionales de Derecho Procesal, FCU, Montevideo.

RISSO FERRAND, Martin (2006). Derecho Constitucional, Tomo I, $2^{\circ}$ Edición, ampliada y actualizada, FCU, Montevideo.

ROCHA, Carolina; BARREIRA, Sebastián (2019). “Admisibilidad y valoración de los documentos electrónicos como medios de prueba. Análisis de la jurisprudencia reciente", XIX Jornadas Nacionales de Derecho Procesal, FCU, Montevideo.

Sentencia Nro. SAN 973/2018 del 09/04/2018, Sección Cuarta de la Sala de lo Penal de la Audiencia Nacional. Recuperado de: http://www.poderjudicial.es/stfls/AUDIENCIA\%20 NACIONAL/JURISPRUDENCIA/AN\%20Penal\%209\%20abril\%202018.pdf

Sentencia STS Nro. 239/2010, de 24 de marzo de 2010 dictada por el Tribunal Supremo - 
Sala Segunda, de lo Penal. Recuperado de: https://supremo.vlex.es/vid/-215145715.

TARIGO, Enrique (1987). "Medios de prueba no previstos expresamente por el Código de Procedimiento Civil", Curso de Derecho Procesal del Instituto Uruguayo de Derecho Procesal, Tomo II, $2^{\circ}$ Edición, FCU, Montevideo.

TARUFFO, Michele (2008). La prueba, Marcial Pons, Madrid.

VALENTIN, Gabriel (2008). "Divorcio causal. Un caso práctico de prueba ilícita", Revista Uruguaya de Derecho de Familia, Vol.17, Nro.20, Montevideo.

VALENTIN, Gabriel (2014). "El principio de la libertad de la prueba y la carga de la prueba", Revista Derecho del Trabajo, Año II, N³, Montevideo.

VALENTIN, Gabriel (2014). La Reforma del Código General del Proceso, FCU, Montevideo.

VALENTIN, Gabriel (2017). "Las reglas para determinar la existencia o inexistencia de los hechos en el proceso jurisdiccional", en VV.AA., Estudios de Derecho Procesal en Homenaje a Eduardo J. Couture, Tomo I, "La prueba en el proceso", La Ley Uruguay, Montevideo.

VESCOVI, Enrique, DE HEGEDUS, Margarita, KLETT, Selva, CARDINAL, Fernando, SIMON, Luis M., PEREIRA, Santiago (1998). Código General del Proceso, Tomo 4, Abaco, Buenos Aires.

Fecha de recepción: 25 de mayo 2020

Fecha de aceptación: 3 de junio 2020. 